УДК 111

DOI: $10.21779 / 2500-1930-2019-34-2-34-40$

\title{
К.К. Абасов
}

\section{Здравый смысл как познавательная деятельность}

Дагестанский государственный университет; Россия, 367001, г. Махачкала, ул. М. Гаджиева, 43a; Kazbek1939@mail.ru

Статья посвящена проблеме взаимодействия здравого смысла с рациональным мышлением. Здравый смысл, как правило, отождествляют с обыденным дорефлексивным мышлением. С одной стороны, он аккумулирует предшествующий опыт успешной деятельности и оказывается своеобразным его выражением, а с другой - представляет собой проект и предписание будущего поведения. Хотя здравый смысл складывается под воздействием обыденной жизни, тем не менее можно говорить и о «научном здравом смысле», опирающемся на выработанные в недрах данной парадигмы стандарты, критерии и традиции и обеспечивающие закрепление наиболее ценного содержания практического опыта в определенных концептуальных структурах.

Основные функции здравого смысла в рамках «нормальной науки» могут быть определены: 1) обеспечение иммунитета, направленного на сохранение данного концептуального основания - господствующей в науке парадигмы; 2) кумулятивное накопление знания; 3) консолидация данного научного сообщества, обеспечивающая его существование и экстенсивное развитие в рамках господствующей парадигмы.

Ключевые слова: здравый смысл, рассудок, разум, парадигма, конкретное тождество, абдукция.

Здравый смысл обладает генетической общностью с обыденным сознанием и прямо или косвенно отождествляется с ним [1, с. 182], поскольку является дорефлексивным мышлением. Однако здравый смысл не ограничивается только обыденным сознанием. В общепринятом толковании мышление на уровне «научного здравого смысла» - это в основном рассудочное мышление, которое не продуцирует новое знание, а лишь истолковывает и объясняет уже существующее, классифицирует и систематизирует факты.

Идеи, выходящие за пределы сложившихся систем, создает разум. Только на уровне разума мышление может постигнуть сущность исследуемых явлений, открыть законы, выражающие существенные, необходимые связи между предметами и явлениями, составными элементами предметов и явлений, между их свойствами.

Проблема соотношения рассудка и разума в познавательном процессе основательнее всего представлена в немецкой классической философии (И. Кант, Г.В.Ф. Гегель).

Согласно Гегелю [2, с. 66], логика здравого смысла или рассудка - формальная логика. В разных контекстах Гегель дает законам формальной логики разные толкования: то он третирует формальную логику, объявляя ее рассадником тавтологий, то требует, чтобы каждая мысль мыслилась во всей строгости, не оставляя ее смутной и неопределенной. 
Но ведь фиксация предмета мысли в его определенности является требованием пренебрегаемой Гегелем формальной логики. Любому рассуждению, как только оно попытается обойтись без реквизита рассудочной логики, грозит опасность превратиться в софистику, о чем и говорит афоризм Гегеля: «Разум без рассудка - это ничто, а рассудок без разума - нечто».

Каждое логически правильное рассуждение или понятие о предмете, согласно закону тождества, должно быть определенным и сохранять свою однозначность на протяжении всего рассуждения и вывода. Основанный на таком понимании закон тождества является необходимым условием правильного мышления, ибо, требуя определенности мысли, указывая на фиксированные сохраняющиеся моменты мышления, он направлен против расплывчатости и беспредметности суждений, против субъективного оперирования гибкостью понятий, могущих в конце концов привести к софистике, к использованию общих положений не для решения реальных задач, а для прикрытия внутренних противоречий заведомо неверных концепций.

Хотя каждый исследуемый объект вступает в многочисленные отношения с другими объектами и не существует вне связи с ними, хотя он непрерывно изменяется, тем не менее он всегда имеет свою специфическую качественную и количественную особенность, и пока он существует как данное качество, обладает относительной устойчивостью, в которой он тождественен самому себе, пока не перейдет в иное качество.

Подчеркивание в законе тождества относительной устойчивости и однозначности, количественной и качественной определенности, тождественности самому себе любого предмета и понятия о нем, является заблуждением не в большей мере чем, скажем, неизбежное огрубление и упрощение познаваемой реальности, возникающее при ее отражении нашим мышлением в виде абстрактных понятий, когда оно (мышление) находится на этапе выработки исходной сетки научных абстракций [3, c. 1415]. Правильно понятый закон тождества не отрицает, как иногда полагают, ни изменчивости тех предметов, которые отображены в относительно устойчивых понятиях, ни изменяемости самих понятий не только в связи с изменением референтов понятий, но и в связи с углублением, обогащением наших знаний в процессе познания. Он не может этого отрицать, хотя бы в силу того, что оперирует устоявшимися понятиями и ничего не говорит о процессе возникновения и становления понятий, о процессах перехода одних понятий в другие, поскольку это не входит в компетенцию формальной логики. Формальная логика лишь абстрагируется от движения и развития мышления, но не отрицает наличие такового, не превращает момент покоя в абсолют. Догматизация и омертвление нашего мышления, превращение момента устойчивости и относительной неизменности положений науки в абсолют и тем самым игнорирование различия, принимая за субстанциональное определение явлений одно лишь тождество, или же наоборот, подчеркивание различия, качественной обособленности вещей, не обращая при этом никакого внимания на их тождественность, свойственны не формальной логике, а метафизике ${ }^{1}$. Правда, формальная логика может также впасть в своего рода метафизику, если абсолютизировать и уни-

\footnotetext{
${ }^{1}$ Термин метафизика в данном контексте употребляется в смысле антидиалектики, а не учения о началах всего сущего.
} 
версализировать ее положения, необоснованно распространяя их за пределы действительной применимости, если допустимое в известных пределах временное отвлечение от развития тех или иных понятий и положений науки заменить отрицанием их развития. Тем более, что между временным отвлечением от развития и полным его отрицанием расстояние небольшое, и если возникнет искушение забыть об этом (избежать чего зачастую очень трудно), можно легко и незаметно для себя превратить формальную логику в метафизику и эклектику.

Формально-логический закон абстрактного тождества, как мы уже отметили, вовсе не отрицает движения и развития мышления, а заранее исключает их из поля своего зрения, элиминирует их, отвлекается от них, рассматривает мышление как совокупность готовых результатов, состоящих из неподвижных истин. Отсюда проистекает ограниченность закона тождества, как и всей формальной логики в целом, но совсем не в том смысле, будто она является альтернативой диалектики, каковой пытался ее представить например, Гегель, приписывая ей метафизическое понимание закона тождества и видя в ней рассадник бесплодных тавтологий.

Речь, следовательно, должна идти не о третировании формальной логики, а о дополнении её.

В процессе познавательной деятельности происходит взаимопереход рассудка и разума. Наиболее характерной формой перехода первого во второе является выход за пределы господствующей парадигмы на основе выдвижения новых фундаментальных теорий.

Ломая ранее сложившиеся системы знания, разум неминуемо выходит за пределы господствующей в науке в данную эпоху парадигмы, следовательно, за пределы здравого смысла эпохи. Теория Эйнштейна, например, вышла за пределы классической парадигмы, но на ее основе создана новая теоретическая система. Лобачевский, выдвигая постулат, противоречащий пятому постулату геометрии Евклида, не только не опирался на здравый смысл эпохи, но и вступал в противоречие с ним. Хотя геометрия Лобачевского выходит за пределы системы геометрии Евклида, тем не менее, она образует строгую систему.

Разум не против системности знания вообще, он против абсолютизации одной какой-то определенной системы, утверждающей себя вечной и незыблемой. «Лучший удел физической теории состоит в том, чтобы указать путь создания новой, более общей теории, в рамках которой она остается предельным случаем» [4, с. 66].

Разум без рассудка может привести к потере ощущения реальности мира, к мистике или иллюзионизму, которые абсолютно чужды научной строгости.

С другой стороны, поскольку рассудок не обладает креативностью - способностью отклоняться от традиционных схем мышления и порождать неортодоксальные идеи [5, с. 194], он может служить оправданием догматизма. Для творческого мышления здравый смысл не гарантирует принятия разумных решений, не защищает исследователя от ошибок.

В силу этого процесс познания бесконечен, а наши представления о мире являются собой некоторой аппроксимацией действительности.

Скептик, апеллируя к здравому смыслу, подчеркивает ненадежность органов чувств, их зависимость от окружающих условий, обычаев, традиций и поэтому рекомендует воздерживаться от суждений, претендующих на истину. Скептицизм признак угасания творческой мысли античных философов в период эллинизма, ибо в 
нем, как отмечал И. Кант, разум действует сам против себя. Однако не следует отрицать и заслуг скептицизма. Он обнаружил слабые места античной гносеологии, противоречия между ощущениями и понятиями, рассудком и разумом, обратил внимание на действительные сложности в сфере познания. Как бы ни был сомнителен скептицизм в отношении позитивном, он всегда силен в своем критическом аспекте, поскольку, как кислота, разъедает всякий догматизм.

Философ, отвергающий скептицизм и обосновывающий принципиальную познаваемость мира, имеет в виду не те или иные единичные факты, а то, что структура мира не заключает в себе абсолютных препятствий для развивающегося познания. В структуре мира, как отмечал Р. Декарт [6, с. 261], не может существовать истин ни столь отдаленных, чтобы они были недостижимы для человеческого разума, ни столь сокровенных, чтобы нельзя было их раскрыть.

Ограниченность здравого смысла обнаруживается особенно резко, когда наука охватывает области, далекие от повседневной практики. Возьмем, к примеру, такой, никак необъяснимый с точки зрения здравого смысла парадокс - относительность одновременности и очередности событий. Пусть в одной системе отсчета событие $A$ происходит во времени перед событием $Б$. В мире классической физики порядок этих событий абсолютен, т. е. во всех системах отсчета событие $A$ происходит раньше события $Б$. Но в мире теории относительности в системе отсчета, движущейся относительно первой со скоростью, близкой к скорости света, очередность событий может оказаться иной. В данном примере парадокс истолкования времени порождается неспособностью здравого смысла выйти за пределы классических представлений о времени и желанием вписать его в привычную форму макромира дорелятивистских эффектов.

Пример из другой области. В чем эстетика шахматной комбинации?

Прежде всего в парадоксальности замысла, в стремлении «не плыть по течению»: ходы, которые на поверхностный взгляд говорят скорее о слабости, чем о силе, выглядят контрастом здравому смыслу. Процесс создания «поэзии шахмат» через полет мысли включает в себя и прелесть новизны (исходная позиция - tabula rasa), и нестандартность рисунка на доске, и скрытость реальной стоимости фигур, и несоответствие между видимостью и сущностью дела, и оригинальность замысла, и парадоксальность идеи (вспомним афоризм Н. Бора: «Эта идея недостаточно безумна, чтобы быть истинной»). Парадоксальный, противоречащий здравому смыслу, ход неожиданно превращается в орудие победы.

Но понятие парадоксальности в шахматах (впрочем, как и в науке) изменяется во времени и пространстве. У начинающих, да и многих разрядников, и сегодня захватит дух при виде жертвы ферзя на $\mathrm{d} 8$ с матом в два хода «а la Мачуский». Мастер же при виде этой парадоксальной и оригинальной в свое время, но уже потерявшей «высокий градус небанальности» и ставшей тривиальной и привычной для восприятия комбинации, только улыбнется. Зато он замрет, когда столкнется с жертвой пешки «ни за что», тогда как новичок пожмет плечами: «Подумаешь пешка».

Ясное осознание того, что «цензура здравого смысла» может стать уздой творческого познания, возникло в науке Нового времени, в которой здравый смысл ценился куда ниже, чем приемы рационального мышления. С большой долей скепсиса к познавательным возможностям здравого смысла относился Ф. Энгельс, утверждая, что здравый рассудок годится только в четырех стенах домашнего обихода, но как 
только он выходит на простор научных исследований начинает переживать самые удивительные приключения [7, с. 21]. Л. Шестов, прямо заявляя, что человек волен так же часто менять свое мировоззрение, как перчатки, требует во всем освобождаться от всяких устоявшихся обыденных представлений, осмеивать здравые суждения и высказывать парадоксы [8].

Однако здравый смысл в зависимости от сферы его применения и направленности, может играть в познании не только негативную, но и позитивную роль. С одной стороны, обобщая прошлый и настоящий опыт и закрепляя его в традиционных суждениях, он консервативен и осмотрителен. Ученый, работающий в рамках здравого смысла, не настроен на выработку оригинальных решений, он занят «наведением порядка» в существующем материале, т. е. проверкой и уточнением известных фактов, а также сбором новых фактов, в принципе предсказанных существующей теорией. Он не стремится создать принципиально новую теорию, более того, он нетерпим к созданию таких теорий другими.

С другой стороны, в условиях, когда рушатся стереотипы, подрывается господствующая парадигма, здравый смысл с его консерватизмом и простыми однозначными понятиями начинает играть стабилизирующую роль. Ведь для любого радикально оригинального знания существует допустимая «мера безумия», превышение которой приводит к потере связи с реальностью, к мистике или иллюзионизму, которые абсолютно чужды научной строгости. Хотя познавательная ценность здравого смысла неравнозначна соответствующему атрибуту научно-теоретического мышления, в их противопоставлении надо знать меру [9, с. 4-6].

Здравый смысл - это не раз и навсегда данная константа. С развитием научного познания (даже в зависимости от типов познавательной культуры) он обновляется. Оригинальные, можно сказать экстравагантные представления, противоречащие здравому смыслу на данном уровне познавательной культуры, со временем вполне укладываются в обновленный здравый смысл. Неудивительно поэтому то, что классическая наука, которая в эпоху становления находилась не в ладах со здравым смыслом, в конце XIX века уже осознавала себя его знаменосцем. Что дало повод биологу Т. Гексли заявить: «Наука - это просто-напросто хорошо натренированный и организованный здравый смысл».

Для современной науки классическая физика представляется близкой к здравому смыслу во многом потому, что она описывает привычную для нас область макроскопических явлений и уже завершивших процесс становления и определившихся в своих свойствах вещей. При этом в стороне от конечного результата остается субъект познания. А неклассическая физика обращается к процессам становления в микромире (квантовая механика) и мегамире (релятивистская космология). Но сфере становления присущи парадоксы, обусловленные ее переходным статусом и принципиальной неустойчивостью явлений. В такой постановке происходит переход от диадной схемы к триединому представлению (субъект познания, внешний мир и познающий арсенал субъекта, который формирует внутренний поток внешних воздействий) $[10$, с. 66$]$.

Подвергая критике дуализм субъекта и объекта как основной принцип «классического мышления», постмодернизм выдвинул тезис о «смерти субъекта познания» классической науки. Однако метафора «смерть субъекта познания», как считает Магомедов К.М., «возвещает не об устранении субъекта вообще, а о «смерти клас- 
сической науки». Здесь подразумевается отказ от кантовской конструкции «чистого разума» и трансцендентального внеисторического и внесоциального субъекта, существующего без конкретного пространственно-временного хронотипа» [11, с. 78-79].

Если здравый смысл апеллирует к устоявшимся в понимании человека нормам и видит во всем что-то уже известное и испытанное, то рациональное мышление для поиска нового использует «абдуктивный подход», который невозможен без интеллектуальной интуиции, воображения и концептуальной смелости [12]. Великие научные открытия, далеко выходящие за пределы здравого смысла, делаются на рискованном пути: в начальный период они неизбежно оказываются лишь догадкой, гипотезой, нередко и с элементами заблуждения. Ни гипотетико-дедуктивный подход, ни индукция через перечисление не могут аргументированно обосновать, какую роль играют изобретательность, воображение и концептуальная смелость в поисках новой концепции. Такой поиск, начиная с обыденного знания и кончая научной теорией, начинается с абдуктивного рассуждения.

Причем абдукцию используют не только в научном, но и во всяком творчестве. В частности, в процессе исследования таинственного происшествия и раскрытия довольно сложной детективной загадки сыщик стремится провести длительное исследование по анализу фактов, а затем по схеме абдуктивных рассуждений найти им объяснительные гипотезы. Дедуктивный метод применяется только для проверки гипотез, уже выдвинутых по схеме абдуктивных рассуждений.

В ряде случаев, когда складываются неопределенные альтернативные ситуации выбора проблем, гипотез, а общепринятые методологии при этом «не работают», своеобразным ориентировочным критерием для исследователя становится здравый смысл. С другой стороны, здравомыслие - лишь предпосылка для творческого мышления, оно не гарантирует полета мысли и принятия разумных решений.

Наконец, отметим, что апелляция к здравому смыслу имеет более широкое распространение в гуманитарных и социальных науках, чем в естественных. Метрика истинности для естественнонаучного знания и метрика истинности для социогуманитарного знания могут различаться полярным образом [13, с. 112].

\section{Литература}

1. Решетова A.E. Здравый смысл в теоретическом мышлении // Вестник Нижегородского университета им. Н.И. Лобачевского. Социальные науки. - 2008. № 1 (9).

2. Гегель Г.В.Ф. Наука логики. Т. 2. - М., 1971.

3. Абасов К.К. Соотношение абстрактного и конкретного тождества // Вестник Дагестанского государственного технического университета. Гуманитарные науки. Вып. 4. - 2003.

4. Эйнштейн А. Собр. науч. трудов: в 4 т. Т. 4. - М., 1967.

5. Малахова Н.Н. Феномен творчества в инновационном обществе // Вестник Дагестанского государственного университета. Сер.: Экономика. Философия. - 2014. - Вып. 5.

6. Декарт Р. Сочинения: в 2 т. Т. 1. - М.: Мысль, 1989.

7. Энгельс Ф. Анти-Дюринг // Маркс К., Энгельс Ф. Соч. Т. 20. 
8. Шестов Л. Апофеоз беспочвенности. Издательский дом: АСТ. - М., 2004. URL: $\quad$ http://uhimik.ru/l-shestov-apofeoz-bespochvennosti-opit-adogmaticheskogomishle/index 2. html\#pages

9. Билалов М.И. Зависимость познавательной культуры от толкования истины // Вестник Московского университета. Сер. 7: Философия. - 2011. - № 2.

10. Семченко E.E. Философия образования: от альтернативных подходов к праксиологии и академизации // KANT. - 2016. - № 4.

11. Магомедов К.М. Проблема субъекта в исламской теологии // Исламоведение. - 2015. - Т. 6. - № 2 .

12. Рузавин Г.И. Абдукция как метод поиска и обоснования объяснительных гипотез // Абдуктивные рассуждения в научном познании. URL: https://studfiles.net/preview/4002048/page:10/

13. Магомедов К.М. Был ли Сократ неграмотным, или о специфике гуманитарного познания // Вестник Дагестанского государственного университета. Сер. 3: Общественные науки. - 2018. - Вып. 1.

Поступила в редакичию 30 апреля 2019 г.

UDC 111

DOI: $10.21779 / 2500-1930-2019-34-2-34-40$

\title{
Common sense as cognitive process
}

\begin{abstract}
K.K. Abasov
Dagestan State University; Russia, 367001, Makhachkala, M. Gadzhiev st., 43a; Kazbek1939@mail.ru

The article is devoted to the problem of interaction of common sense with rational thinking. Common sense is generally identified with ordinary pre-reflexive thinking. On the one hand, it accumulates the previous experience of successful activity and turns out to be a kind of its expression, and on the other - it is a project and an order of future behavior. While common sense is shaped by everyday life, it is nevertheless possible to speak of «scientific common sense», which provides for the consolidation of the most valuable rational content of practical experience in certain conceptual structures.

The main functions of common sense in the framework of «normal science» can be defined as: 1) protective in relation to the dominant paradigm; 2) consolidating in relation to the scientific community, ensuring its existence and extensive development within the framework of the dominant paradigm.
\end{abstract}

Keywords: common sense, mind, reason, paradigm, specific identity, abduction.

Received 30 April, 2019

40

Вестник Дагестанского государственного университета.

Серия 3. Общественные науки. 2019. Том 34. Вып. 2 